\title{
Fatigue life estimation for different notched specimens based on the volumetric approach
}

\author{
M. Zehsaz ${ }^{1}$, S. Hassanifard ${ }^{2, a}$, and F. Esmaeili ${ }^{3}$ \\ ${ }^{1,2,3}$ Building No. 8, Faculty of Mechanical Engineering, University of Tabriz, Tabriz, Iran
}

\begin{abstract}
In this paper, the effects of notch radius for different notched specimens has been studied on the values of stress concentration factor, notch strength reduction factor, and fatigue life duration of the specimens. The material which has been selected for this investigation is $\mathrm{Al} 2024 \mathrm{~T} 3$. Volumetric approach has been applied to obtain the values of notch strength reduction factor and results have been compared with those obtained from the Neuber and Peterson methods. Load controlled fatigue tests of mentioned specimens have been conducted on the $250 \mathrm{kN}$ servo-hydraulic Zwick/Amsler fatigue testing machine with the frequency of $10 \mathrm{~Hz}$. The fatigue lives of the specimens have also been predicted based on the available smooth S-N curve of A12024-T3 and also the amounts of notch strength reduction factor which have been obtained from volumetric, Neuber and Peterson methods. The values of stress and strain around the notch roots are required to predict the fatigue life of notched specimens, so Ansys finite element code has been used and non-linear analyses have been performed to obtain the stress and strain distributions around the notches. The plastic deformations of the material have been simulated using multi-linear kinematic hardening and cyclic stress-strain relation. The work here shows that the volumetric approach does a very good job for predicting the fatigue life of the notched specimens.
\end{abstract}

\section{Introduction}

Components of machines are usually subjected to the cyclic loads and the resulting cyclic stresses can lead to microscopic physical damage to the materials involved. Fatigue fractures usually occur at the notches such as holes, grooves, etc. The geometry of notch and other notch properties affect on the predictions of fatigue life. Stress at the notch is equal to the nominal stress multiplied by the elastic stress concentration factor, $k_{t}$. This stress rise will of course be very harmful with respect to fatigue damage, but it can not give directly the effective stress range in fatigue. Therefore, the fatigue strength reduction factor $k_{f}$ should be introduced.

In fatigue design, diagram of amplitude stress versus the number of cycles also called $\mathrm{S}-\mathrm{N}$ curve are frequently used [1].

There is not a general experimental method with low cost to obtain the $k_{f}$ values, and this is because of the micro-mechanical complications and uncertainties of the plastic zone in the notch root [2].

This is an Open Access article distributed under the terms of the Creative Commons Attribution-Noncommercial License 3.0, which permits unrestricted use, distribution, and reproduction in any noncommercial medium, provided the original work is properly cited. 
A general definition of the notch strength reduction factor is the ratio of fatigue strength of smooth specimen to fatigue strength of the notched specimen in the same numbers of cycles and the same experimental test conditions [3]:

$$
k_{f}=\frac{\sigma_{s}}{\sigma_{n}}
$$

where $\sigma_{s}$ and $\sigma_{n}$ are the fatigue strength of smooth and notched specimens, respectively. To express difference of the notch strength reduction factor $k_{f}$ and the elastic stress concentration factor $k_{t}$, notch sensitivity is introduced. Three different definitions have been proposed for notch sensitivity as follows:

$$
\begin{aligned}
& q=\frac{k_{f}-1}{k_{t}-1} \\
& q=\frac{k_{f}}{k_{t}} \\
& q=\frac{k_{f}}{k_{\sigma}}
\end{aligned}
$$

where in Eq. $4, k_{\sigma}$ is the elastic-plastic stress concentration factor. There are several experimental relations to express notch sensitivity factor in terms of notch radius. However, the accuracy of these relations is not very clear and it is essential to carry out more experimental tests.

Notch sensitivity factor for describing the notch effects of the high-cycle fatigue problems have some disadvantages while definition of the relations between $k_{f}$ and $k_{t}$, as follows:

1) There are some experiment dependent coefficients which have been obtained for materials used in many years ago. Nowadays, since varieties of materials in industry are ever increasing and new materials and alloys have been produced, using these coefficients is not very appropriate.

2) Differences between these relations are high and the accuracy of these relations is not clear.

3) The effects of net stress and stress gradient in these relations have been neglected.

In the present study, among the relations that have been proposed to describe the notch sensitivity factor, Peterson [4] and Neuber [5] are introduced.

Peterson assumed that the fatigue failure occurs when the stress at one point which has a critical distance from the notch root $\left(a_{p}\right)$ is equal to the fatigue strength of smooth specimen. Assuming that the stress near the notch root is decreasing linearly, Peterson proposed the following experimental relation:

$$
q=\frac{1}{1+\frac{a_{p}}{r}}
$$

where $r$ is notch radius and $a_{p}$ is material constant which depends on the grain size and loading. Figure 1 shows the amounts of notch sensitivity versus notch radius for steel and aluminium based on Peterson's relations. 


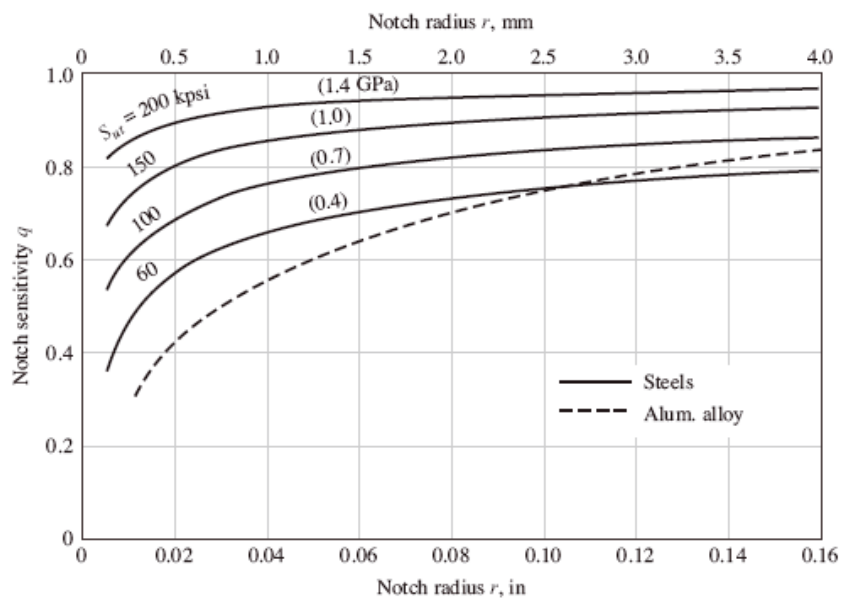

Fig. 1. Notch sensitivity versus notch radius for steels and aluminium alloys.

Neuber assumed that fatigue failure occurs when the mean stress with distance of $a_{N}$ from the notch root is equal to the fatigue strength of smooth specimen. Neuber's relation can be described as follows:

$$
q=\frac{1}{1+\sqrt{\frac{a_{N}}{r}}}
$$

where $a_{N}$ is the material constant which depends on the grain size. Figure 2 shows the Neuber's constant $a_{N}^{\frac{1}{2}}$ versus ultimate tensile strength for aluminium alloys.

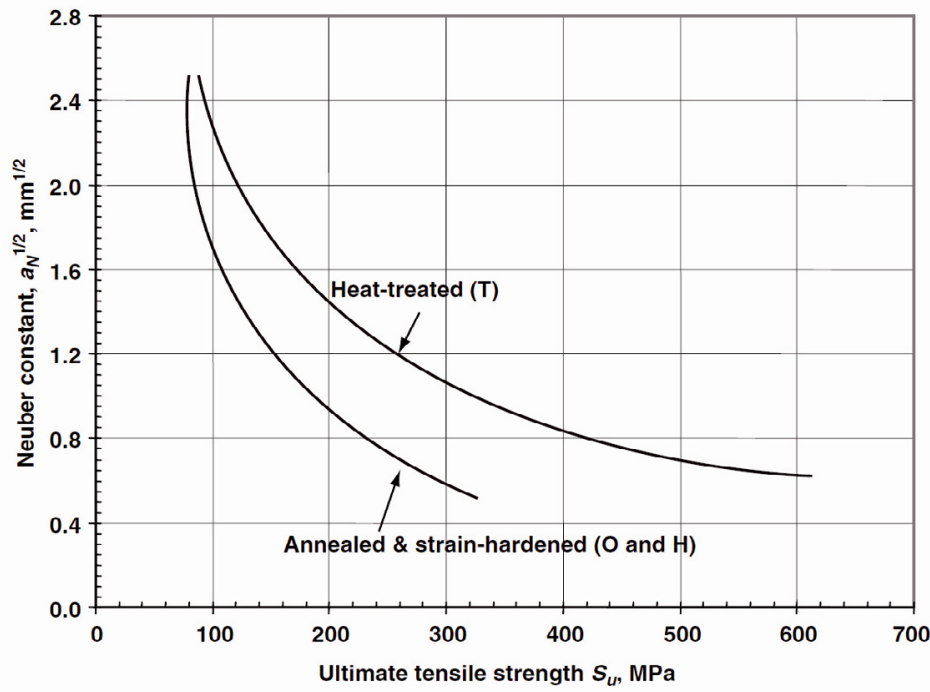

Fig. 2. Neuber's constant versus ultimate tensile strength for aluminium alloys. 


\section{Basic principals of volumetric approach to study the fatigue life}

Two major elements indicate that the fatigue mechanism requires a physical volume to take place; fatigue tests are generally affected by a large scatter and fatigue resistance is influenced by the size of specimen and the relative stress gradient which are dimensional parameters. This approach leads to a two parameter fatigue initiation criterion, the effective stress and the effective distance. The effective distance is associated with a particular point of the elastic-plastic stress distribution presented in a bi-logarithmic graph. The effective stress corresponds to an average value over this distance of the stress distribution weighted by the distance and the relative stress gradient $[6,7]$.

A typical elastic-plastic stress distribution near a notch has been shown in Figure 3.

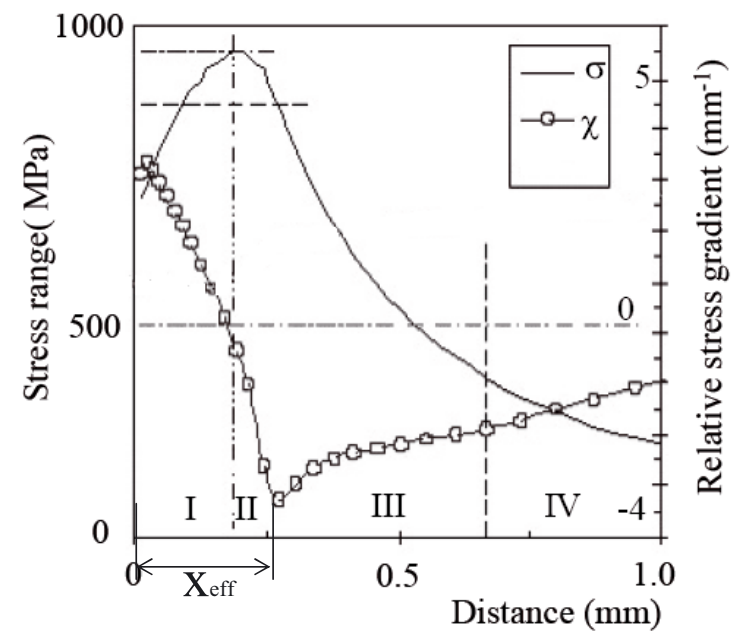

Fig. 3. A typical elastic-plastic stress distribution near a notch [6].

Three different zones can be distinguished from Figure 3. The maximum stress and its distance can be clarified in zone I. The important characteristic of this zone is the existing of maximum stress in elastic-plastic stress distribution which has been obtained from finite element (FE) analysis. The elastic FE analysis in notch root for the crack opening stress reveals that stress value is decreasing from the notch root toward the outside $[8,9]$. In zone II, the stress value is decreasing and its value reaches to the effective stress $\sigma_{\text {eff }}$. In other words, zone II is a transient zone.

The limit between region II and III can be considered as the effective distance with a high degree of confidence. According to the volumetric approach, fatigue strength reduction factor is given by the following formula:

$$
k_{f}=\frac{1}{X_{e f f} \sigma_{n}} \int_{0}^{X_{e f f}} \sigma_{y y}(x)(1-x \chi) d x
$$

where $X_{\text {eff }}$ is the effective distance, $\sigma_{n}$ is net stress, $\sigma_{y y}$ is the crack opening stress, and $\chi$ is relative stress gradient which is defined as follows:

$$
\chi=\frac{1}{\sigma(x)} \frac{d \sigma(x)}{d x}
$$

In this approach, fatigue life prediction can be fulfilled using the reference curve of smooth specimen, mechanical properties and notch strength reduction factor values [1]. 


\section{Experiments}

The specimens employed in this investigation were manufactured from 2024-T3 aluminium alloy with thickness of $2 \mathrm{~mm}$, whose mechanical properties and chemical compositions have been presented in Tables 1 and 2, respectively. Test specimen configuration for the elliptical hole has been shown in Figure 4, for instance.

Table 1. Mechanical properties of 2024-T3 aluminium alloy.

\begin{tabular}{ccccc}
\hline \hline $\begin{array}{c}\text { Young's modulus } \\
(\mathrm{GPa})\end{array}$ & $\begin{array}{c}\text { Yield stress } \\
(\mathrm{MPa})\end{array}$ & $\begin{array}{c}\text { Tensile strength } \\
(\mathrm{MPa})\end{array}$ & $\begin{array}{c}\text { Poisson's } \\
\text { ratio }\end{array}$ & $\begin{array}{c}\text { Elongation } \\
(\%)\end{array}$ \\
\hline 73.4 & 315 & 550 & 0.33 & 0.18 \\
\hline \hline
\end{tabular}

Table 2. Chemical composition of 2024-T3 aluminium alloy.

\begin{tabular}{ccccccccc}
\hline \hline $\mathrm{Cu}$ & $\mathrm{Mg}$ & $\mathrm{Mn}$ & $\mathrm{Fe}$ & $\mathrm{Si}$ & $\mathrm{Cr}$ & $\mathrm{Zn}$ & $\mathrm{Ti}$ & $\mathrm{Al}$ \\
\hline 4.82 & 1.67 & 0.58 & 0.18 & 0.07 & 0.02 & 0.06 & 0.15 & $\mathrm{Bal}$ \\
\hline \hline
\end{tabular}

The values are in percentages

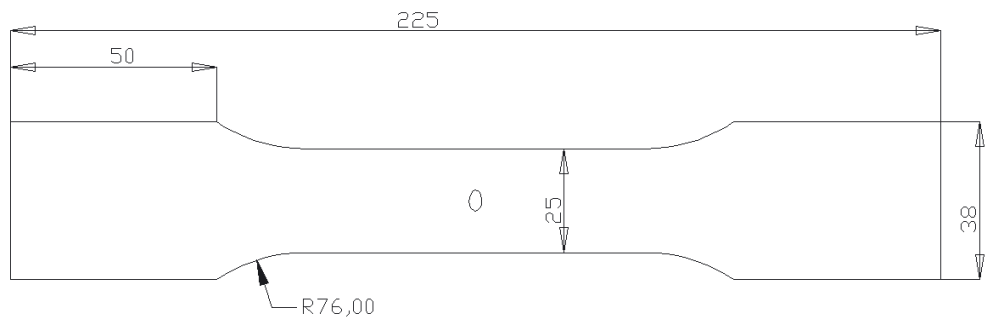

Fig. 4. Test specimen configuration for the elliptical notch.

Fatigue tests have been carried out for stress ratio of 0.1 and frequency of $10 \mathrm{~Hz}$ using servohydraulic $250 \mathrm{kN}$ Zwick Roell fatigue testing machine.

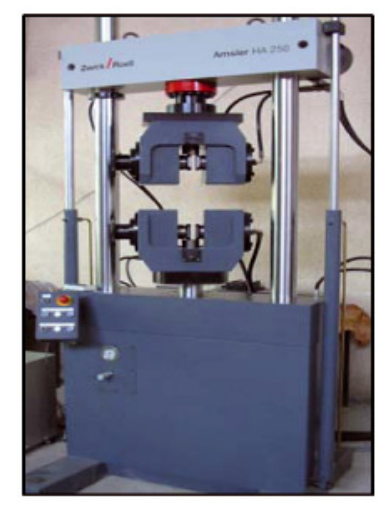


Fig. 5. Amsler HA250 kN Fatigue testing machine.

Figure 6 shows the true stress-strain curve of 2024-T3 aluminium alloy.

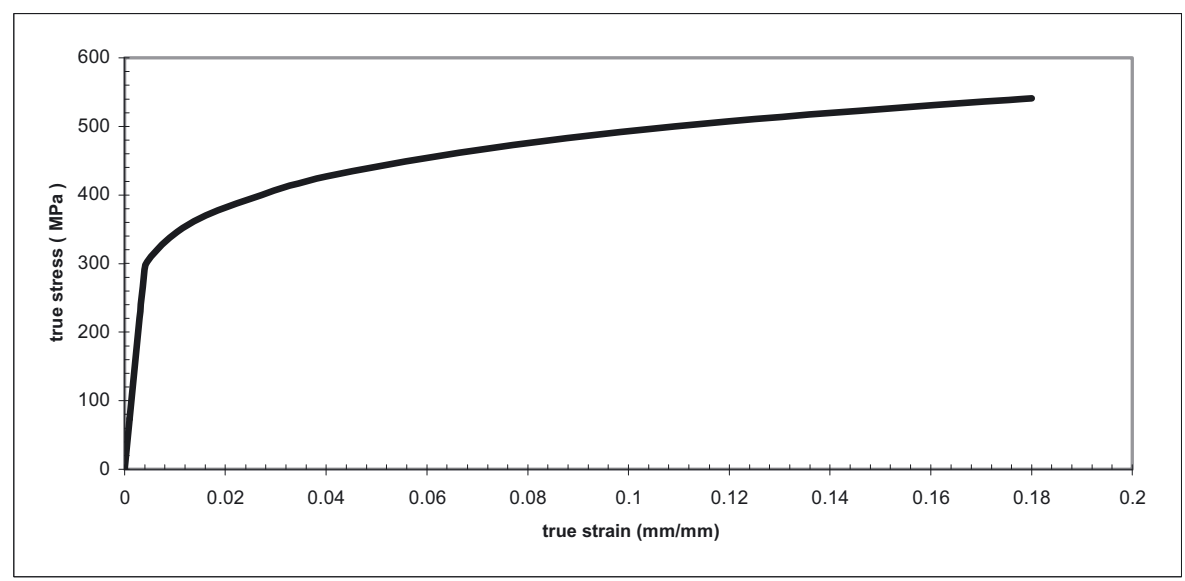

Fig. 6. True stress-strain curve of 2024-T3 aluminium alloy.

\section{Finite element analysis}

As mentioned earlier, to obtain the effective distance and effective stress values and also the notch strength reduction factors in volumetric approach, finite element analysis has been employed. In the present investigation, to estimate the fatigue life of sheets with different notches (Figure 7), three dimensional models of sheets have been simulated using Ansys FE code, and solid95 20-node structural element has been used. To extract more accurate results, mapped mesh with sufficiently fine mesh around the notches has been used in FE analyses.
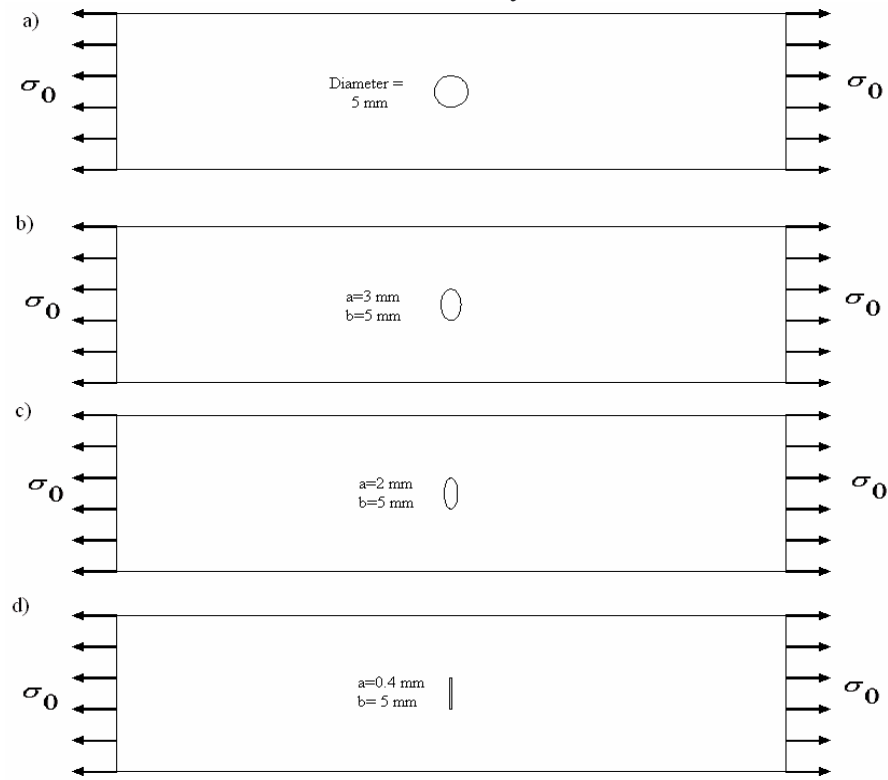
Fig. 7. The configuration of test samples and FE models with different notches.

A quarter of meshed model of a notched specimen with applied boundary conditions and loading has been shown in Figure 8.

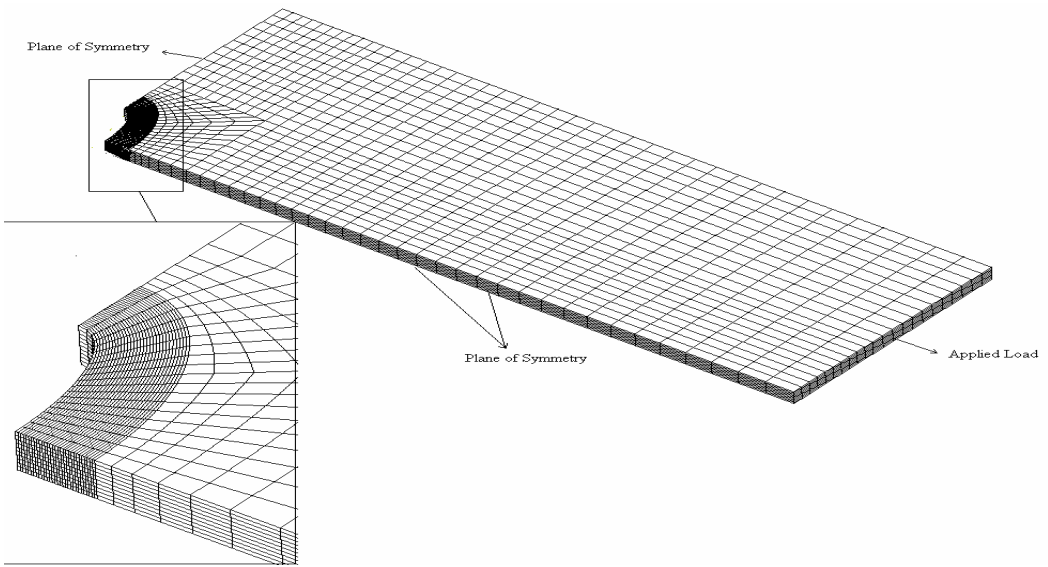

Fig. 8. A quarter of meshed model of a notched sample with applied boundary conditions.

The elastic-plastic behaviour of 2024-T3 aluminium alloy has been considered to simulate the strain hardening effect of material and for this reason the kinematic strain hardening model has been employed. Figures 9-12, show the crack opening stress and relative stress gradient distributions versus distance from notch roots toward the sheet edges.
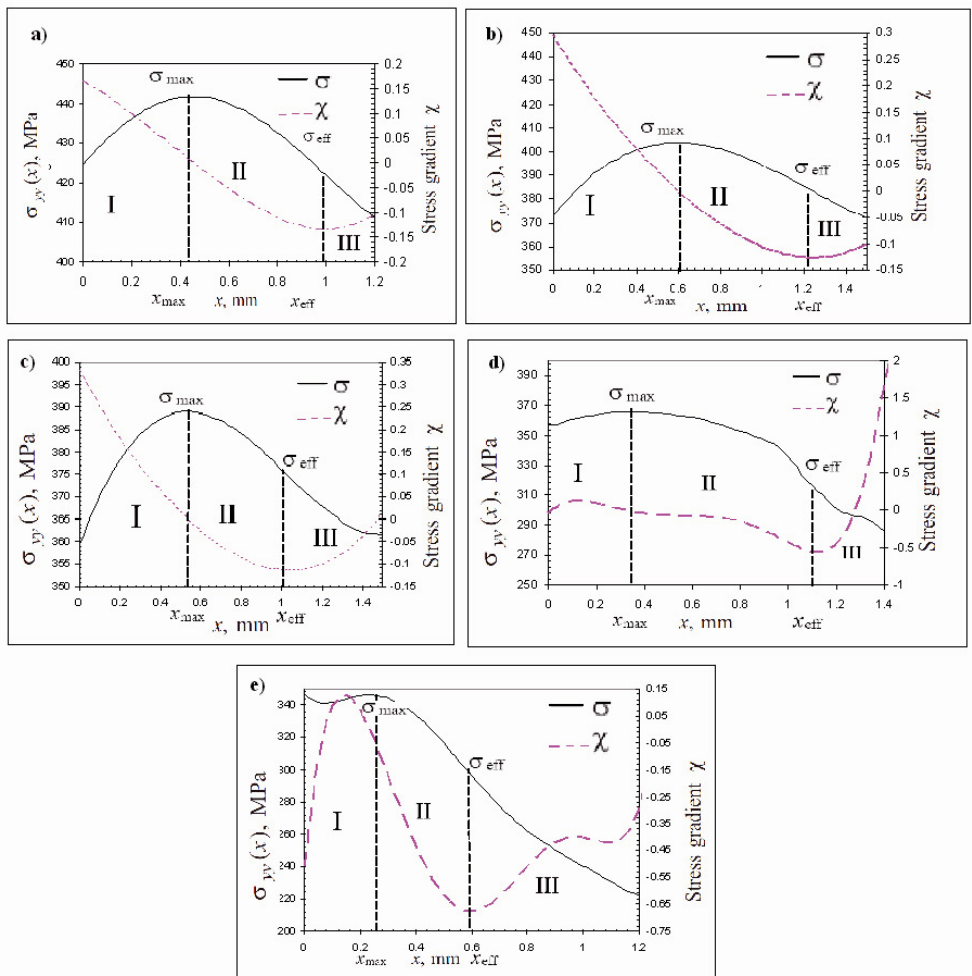
Fig. 9. Crack opening stress and relative stress gradient distributions for the samples with the circular holes at different levels of static fracture load; a) $80 \%$ b) $70 \%$ c) $60 \%$ d) $50 \%$ and e) $40 \%$ of static fracture load.
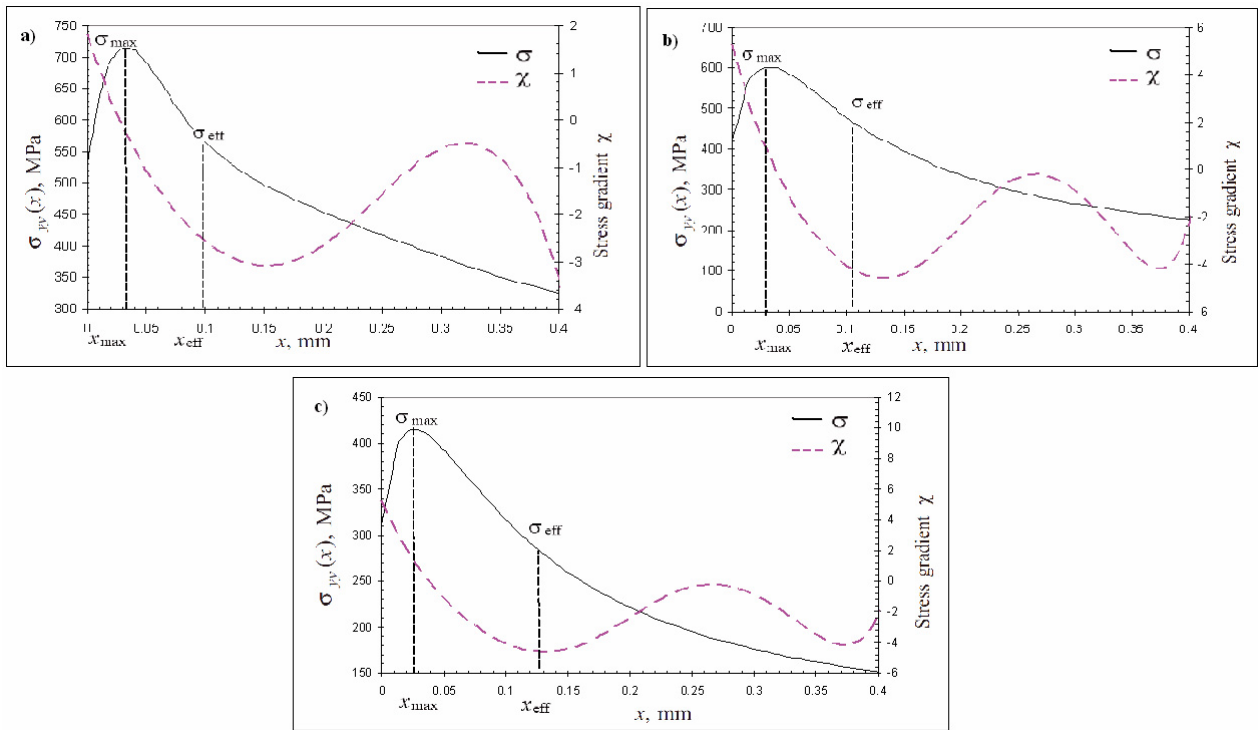

Fig. 10 Crack opening stress and relative stress gradient distributions for the samples with the elliptical holes ( $a=0.4 \mathrm{~mm}, \mathrm{~b}=5 \mathrm{~mm}$ ) at different levels of static fracture load; a) $40 \%$ b) $30 \%$ and c) $20 \%$ of static fracture load.
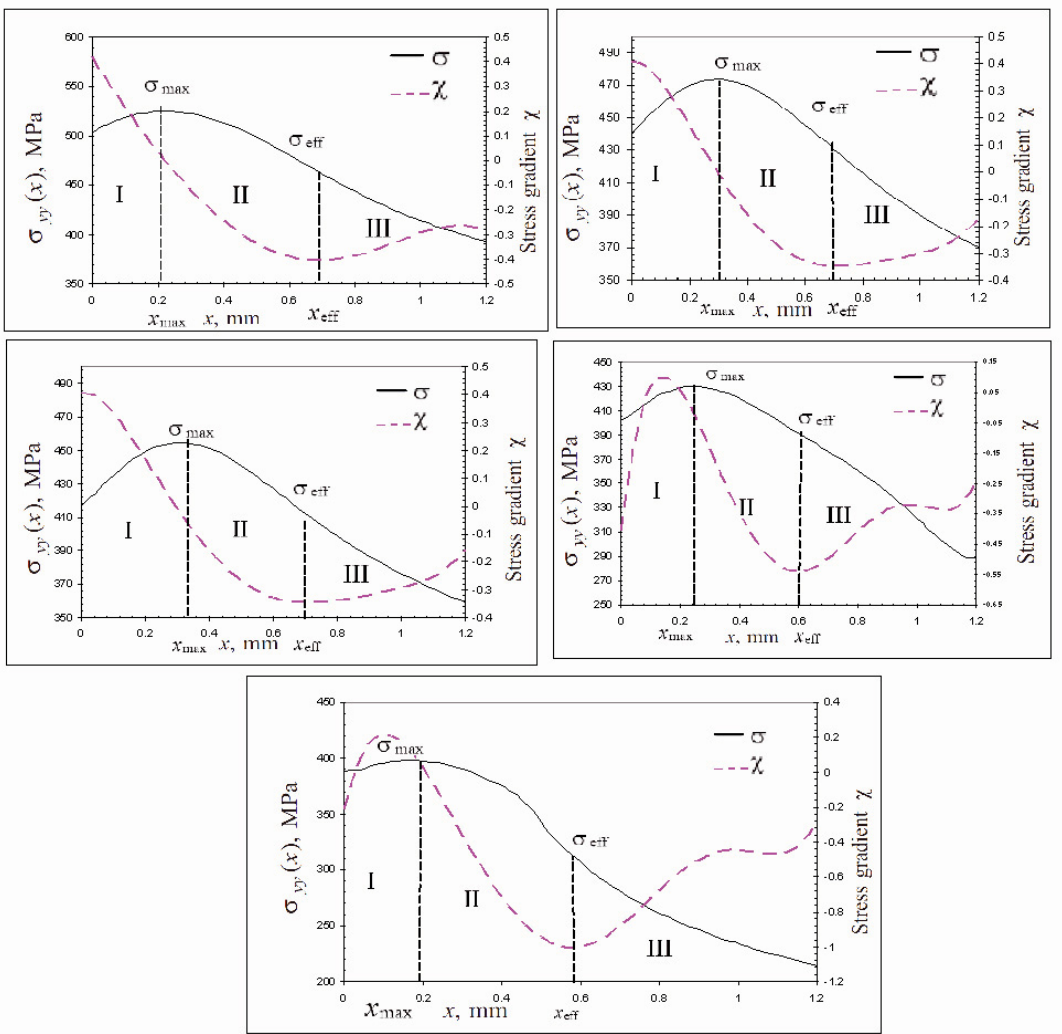
Fig. 11 Crack opening stress and relative stress gradient distributions for the samples with the elliptical holes $(a=3 \mathrm{~mm}, b=5 \mathrm{~mm}$ ) at different levels of static fracture load a) $80 \%$ b) $70 \%$ c) $60 \%$ d) $50 \%$ and e) $40 \%$ of static fracture load.
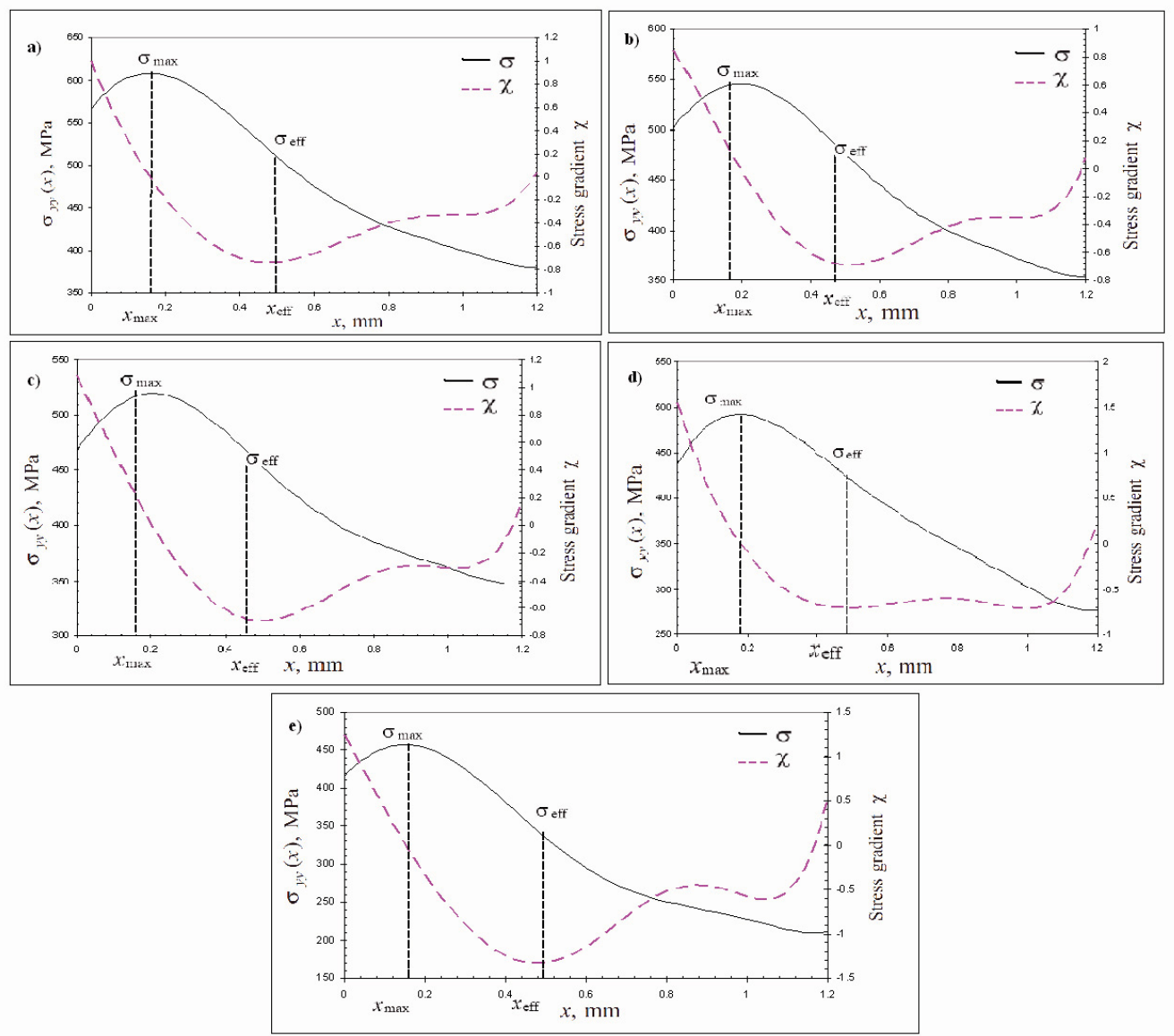

Fig. 12 Crack opening stress and relative stress gradient distributions for the samples with the elliptical holes ( $a=2 \mathrm{~mm}, \mathrm{~b}=5 \mathrm{~mm}$ ) at different levels of static fracture load a) $80 \%$ b) $70 \%$ c) $60 \%$ d) $50 \%$ and e) $40 \%$ of static fracture load.

\section{Results and discussion}

In this section, to investigate the validity and accuracy of the volumetric approach with other previously mentioned methods, the fatigue life experimental results have been compared with those obtained from the volumetric, Neuber and Peterson methods.

Figure 13 shows the fatigue strength versus the number of cycles to failure for different notched specimens based on the mentioned approaches. As it can be seen in this Figure, the volumetric approach has good agreement with experimental test results and has relatively higher accuracy compared with Neuber and Peterson methods.

The results based on Peterson method for the load levels with high stress concentration are not very accurate. Neuber method in high cycle fatigue regions present relatively weak results compared with other methods. However, the volumetric approach with all levels of loads and for all kinds of notches presents very good and reasonable results. 


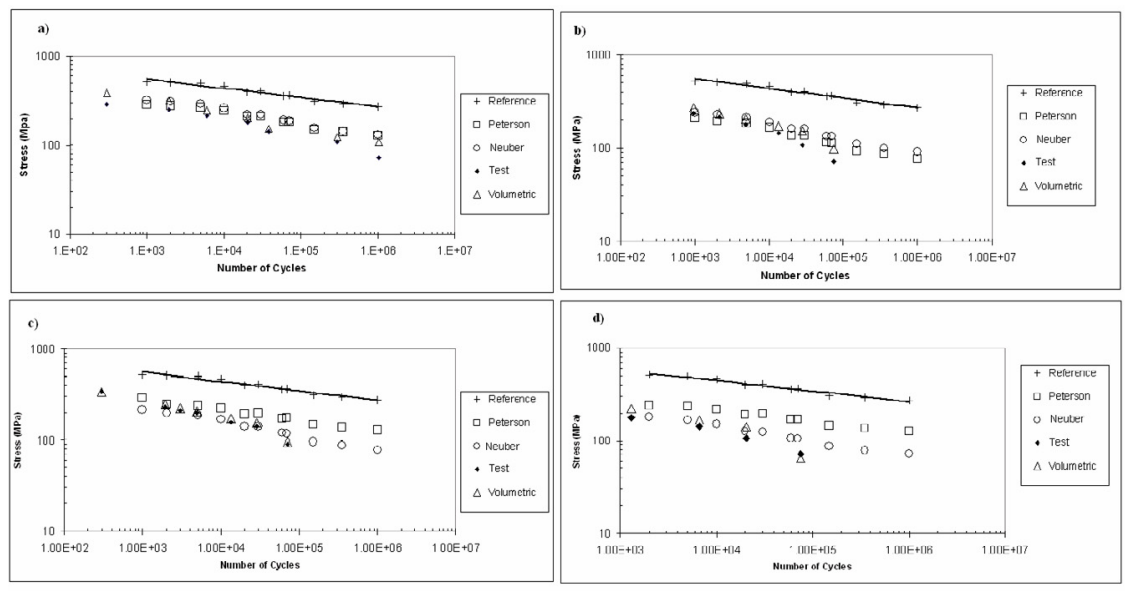

Fig. 13. Fatigue strength versus the number of cycles to failure for different notched specimens based on the volumetric approach, Neuber and Peterson methods, and comparison with experimental results.

\section{Conclusions}

In the present study, the effects of notch radius for different notched specimens has been investigated based on the volumetric approach and results have been compared with those obtained from the Neuber and Peterson methods. The values of stress and strain around the notch roots were obtained to predict the fatigue life of notched specimens. The work here showed that the volumetric approach does a very good job for predicting the fatigue life of the notched specimens.

\section{References}

1. H. Adib, and G. Pluvinage, Theoretical and numerical aspects of the volumetric approach for fatigue life prediction in notched components. International Journal of Fatigue, 25 (2003).

2. VE., Panin, Foundation of physical meso-mechanics. Phys Mesomech Russian Academy of Sciences, 1:5-20 (1998).

3. P. Kuhn, and HF. Hardraht, An engineering method for estimating the notch-size effect in fatigue tests on steel, NACA TN2805. Washington:Langly Aeronautic Laboratory (1952).

4. R.E. Peterson, Notch sensitivity, Metal Fatigue (Edited by G. Sines \& J.L.Waisman). MacGraw Hill, New York (1959).

5. H. Neuber, Kerbspannungslehre. Springer, Berlin (1958).

6. G. Pluvinage, Application of notch effect in high cycle fatigue. In Proceedings of the 9th International Conference on Fracture, ICF9. Advances in fracture research, vol. 3: Fatigue of metallic and non-metallic materials and structures. Pergamon (1997).

7. G. Pluvinage, Application of notch fracture mechanics to fracture emanating from stress concentrators. Advances in Computational Engineering Congress of Computational Engineering Sciences (1997).

8. SQ. Shi, and MP. Puls, A simple method of estimating the maximum normal stress and plastic zone size at a shallow notch, Int J Pressure Vessel Piping 64:67-71( 1995).

9. M. Zheng, and E. Niemi, Analysis of the stress concentration factor for a shallow notch by the slip-line field method. Int J Fatigue 19(3):191-4 (1997). 